Trascendencia de la lúdica como dimensión psicoespiritual en el proyecto de vida de los actantes educativos Nerio J. Ramírez Almarza (10:23)

\title{
TRASCENDENCIA DE LA LÚDICA COMO DIMENSIÓN PSICOESPIRITUAL EN EL PROYECTO DE VIDA DE LOS ACTANTES EDUCATIVOS
}

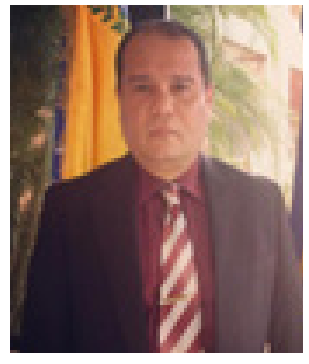

Fecha de recepción: 01/03/2018

\section{Nerio J. Ramírez Almarza}

Universidad Nacional Experimental Rafael María Baralt, Venezuela nerioramirezalmarza@gmail.com

\section{RESUMEN}

La educación es uno de los elementos esenciales del ser humano y de la sociedad, por tal motivo, los centros de formación deben dar respuestas constantes y oportunas a todo el conglomerado de actantes educativos; de allí que la investigación titulada: Trascendencia de la lúdica como dimensión psicoespiritual en el proyecto de vida de los actantes educativos; y la cual está fundamentada en Newson (1986), Cabrera (2009), Flaceiére (1993), Universidad del Norte (2010), Cordero (2010), Jiménez (2007), Beltrán (2002), Medina (2014), Echeverry y Gómez (2009), Paredes (2003), García (2004). La indagación tiene la finalidad de analizar la trascendencia de la lúdica como dimensión psicoespiritual en el proyecto de vida de los actantes educativos; cuyo abordaje epistemológico se enmarcó en un enfoque cualitativo, bajo la metodología centrada en una revisión bibliográfica. Llegando a la conclusión de que la lúdica como dimensión psicoespiritual, va a transformar el proceso de enseñanza-aprendizaje, puesto que, son los actantes educativos los protagonistas de dicho proceso; y a su vez como dimensión; ya que encamina al hombre al desarrollo emocional y a los talentos personales, ayudando con ello a alcanzar su felicidad; se sugiere a los docentes a nivel andragógico que, diseñen actividades, encuentros, convivencias, ejercicios, que persigan no solo el disfrute de esos actos, sino del crecimiento psicológico y espiritual de los actantes educativos.

Palabras Clave: Lúdica, Actitud, Vida, Actantes Educativos, Psicoespiritual. 


\title{
TRANSCENDENCE OF LYRIC AS A PSYCHO-SPIRITUAL DIMENSION IN THE LIFE PROJECT OF EDUCATIONAL ACTANTS
}

\begin{abstract}
Education is one of the essential elements of the human being and of society, for this reason, the training centers must give constant and timely answers to the whole conglomerate of educational actants; hence the research entitled: Transcendence of the playful as a psycho-spiritual dimension in the life project of educational actants; and which is based on Newson (1986), Cabrera (2009), Flaceiére (1993), Universidad del Norte (2010), Cordero (2010), Jiménez (2007), Beltrán (2002), Medina (2014), Echeverry and Gómez (2009), Paredes (2003), García (2004). The purpose of the inquiry is to analyze the transcendence of the playful as a psycho-spiritual dimension in the life project of educational actants; whose epistemological approach was framed in a qualitative approach, under the methodology focused on a bibliographic review. Arriving at the conclusion that the playful as psychospiritual dimension, will transform the teaching-learning process, since, are the educational actors the protagonists of this process; and in turn as a dimension; since it directs the man to the emotional development and to the personal talents, helping with it to reach his happiness; It is suggested to the teachers at an andragogic level that they design activities, meetings, coexistence, exercises that pursue not only the enjoyment of those acts, but the psychological and spiritual growth of the educational actants.
\end{abstract}

Keywords: Playful, Attitude, Life, Educational Actors, Psycho-Spiritual.

\section{INTRODUCCIÓN}

El ser humano siempre ha tenido el interés de formarse y educarse, para desarrollar su micro y macro entorno; desde el inicio de su hominización el hombre ha buscado y creado estrategias con el fin de optimizar el proceso formativo, una de las estrategias es la lúdica, que por medio de diversas actividades se ha convertido en una herramienta pedagógica con el cual se fortalecen los aprendizajes en los actantes educativos (docentes y alumnos).

De tal manera que la lúdica no puede ser sinónima exclusivo de juegos o entretenimientos, sino más bien de aquella realidad que puede desarrollar la parte física, psicológica y espiritual de los actantes educativos, así como también puede ser utilizada como una dimensión psicoespiritual que conlleve a una actitud frente a la vida con el sentido de darle alcance al equilibrio personal, social, cultural y vocacional de la persona, buscando que el ser humano aprenda a desarrollar una un proyecto de calidad de vida personal y profesional. 
Trascendencia de la lúdica como dimensión psicoespiritual en el proyecto de vida de los actantes educativos Nerio J. Ramírez Almarza (10:23)

Por esas consideraciones, la investigación generará un aprendizaje actual sobre la lúdica; de tal manera que, el estudio tiene como finalidad, analizar la trascendencia de la lúdica como dimensión psicoespiritual en el proyecto de vida de los actantes educativos, dicha indagación se considera significativa puesto que busca transformar la dinámica lúdica en el proceso educativo sobre todo en el área andragógica.

En relación a las consideraciones metodológicas, se puede decir que, el estudio se orientó a través de una revisión bibliográfica, en la cual se recopiló lo más esencial y relevante sobre la lúdica como dimensión psicoespiritual, soportada por diferentes enfoques que contribuyeron al establecer una serie de criterios para el análisis correspondiente del estudio.

Por tal, lo trascendente del estudio es que aporta y profundiza lo concerniente a la dimensión psicoespiritual de la lúdica; con la intensión de ampliar el conocimiento en pro del crecimiento personal y profesional, debido a que la educación es un referente humanístico, en el crecimiento integral de la persona y de la sociedad.

\section{La Lexía Lúdica, su Historia y Etimología}

Como toda palabra, la lexía lúdica ha progresado en la sociedad, desde su aparición en la lengua latina, la cual proviene de Ludus; y que según su etimología significa juego, sin embargo, al leerla en diferentes textos, se podría pensar exclusivamente en la acepción de juego, recreación, esparcimiento, ocio, diversión, entre otras. Ahora bien, en la actualidad la lúdica va más allá de un simple entretenimiento o de una estrategia pedagógica exclusivamente infantil, debido a que, lo lúdico es una categoría mayor al juego y en consecuencia el juego es otra de las tantas manifestaciones de lo lúdico.

Partiendo de lo antes expuesto, y para tener más claridad en lo referente al juego y diferenciarlo de la lúdica; se puede decir que, el juego es una actividad que tiene un entono de libertad y espontaneidad y va ligado a algunas reglas preestablecida con el fin de que se cumplan y de obtener la victoria al desarrollar la competencia; cabe agregar que, para Montessori, citado por Newson (1986), pensaba en su tiempo y espacio que el juego se define como una "actividad lúdica organizada para alcanzar fines específicos" (p.26); mientras que la lúdica, tiene un propósito, basándose en los contenidos de forma dinámica para aprender algo; por tal, cualquier juego es lúdico, pero no toda lúdica es juego. 


\section{El juego y la Lúdica}

Al acudir a la historia, se puede percibir como para los griegos, según Cabrera (2009), los juegos tradicionales infantiles eran el máximo exponente dentro de la cultura lúdica de un pueblo; y que por los elementos climáticos, en muchos juegos se prescindía de los juguetes, puesto que los juegos, se hacían al aire libre. Para ese tiempo, a los infantes se les clasificaba según la edad, así pues, estaban los de ocho a once años, los cuales eran considerados chiquillos o lobeznos; entre los doce y quince se llamaba muchacho y de los diecisiete a veinte se le conocía como íren; es decir efebo de primero, segundo, tercero o cuarto año.

De igual manera Flaceiére (1993), señala que, gracias a los restos arqueológicos hay vestigios de figuras de juguetes de barro cocido como sinajeros, caballos con rueda, muñecas, así como matraca (platage), yoyó, pelotas (sphaira), trompo (strómbos), escondite (kriptínda), la soga (helkistida), soldaditos (basilinda), igualmente, carros, vajillas, animales, y que los niños los obtenían como regalos por las fiestas de Diasias o Antesterias.

Uno de los juegos más importante era el conocido como el de las tabas (huesos), el cual se basaba en lanzar a modo de dado al suelo o sobre una mesa; y que las distintas caras de la taba tienen formas diferentes y por lo tanto distinta probabilidad de salir; otro juego común era el denominado como el de míada, el cual le tapaban los ojos a un infante y los demás le gritaban para ver si podían atraparle, este juego es conocido en muchos países en la actualidad como gallina ciega. Entre los juegos se perseguía que los participantes desarrollaran las habilidades, destrezas, imaginación, creatividad, respeto de las normas, flexibilidad física (juegos gimnásticos), entre otras.

En el caso de los romanos, según la Universidad del Norte (2010), la organización escolar estaba dividida en tres grandes niveles, a los que corresponden tres tipos de escuelas: la elemental, la media y la superior, en el caso de la escuela elemental, era llamada ludus litterarius (juego literario), entendiendo la referencia al "juego" como a una actividad alejada de toda connotación práctica.

Para los antiguos, el saber cómo actividad y cómo resultado es desinteresado, vale y debe buscárselo por sí mismo (aunque luego sus aplicaciones en la vida cotidiana proporcionen alguna utilidad), humaniza al hombre, planificando sus capacidades específicas, es significativo exponer que como concesión a los más pequeños, el magister ludi le daban letras hechas de hueso o de marfil para que jugaran con ellas y comenzaran a reconocerlas, y también los premiaban con tortas con la forma de la letra que acababan de aprender. 
Trascendencia de la lúdica como dimensión psicoespiritual en el proyecto de vida de los actantes educativos Nerio J. Ramírez Almarza (10:23)

Dentro de los juegos más conocidos en la población infantil romana, se encontraban: muñecas, entablar luchas, la morra (adivinar cuantos dedos sacaría el contrario), las canicas, las tabas, fichas, dados, el aro, pares o nones, la mosca de bronce, caput aut navis (cara o cruz), Mormolycium (dar sustos), Micare (moverse rápidamente); de tal manera que, la lúdica como juego ha sido una técnica de aprendizaje habitual a través de los tiempos, la cual ha servido para fomentar el trabajo en equipo, favorecer la sociabilidad, desarrollar la capacidad creativa, la crítica y la comunicación del individuo, a la vez que estimula la acción, reflexión y la expresión.

Por otra parte, Platón (Leyes, 7, 793 e), aconsejaba que se dejara jugar a los niños al aire libre hasta los seis años, no sin dirigir sus juegos con vistas al aprendizaje de un futuro oficio; cabe agregar que, Platón consideraba que la educación se basaba en el juego y estimaba que se debía comenzar por la música para la formación del alma y posteriormente con la educación física para el cuerpo, de igual manera, Aristóteles enfatizaba y diferenciaba la actividad lúdica entre el juego físico y el juego más elaborado dirigido a otros fines.

El propio Aristóteles que se ocupa de los problemas educativos para la formación de hombres libres, menciona en varios lugares de sus obras, ideas que remiten a la conducta de juego en los niños: el cual afirmaba que hasta la edad de cinco años, tiempo en que todavía no es bueno orientarlos a un estudio, ni a trabajos coactivos, a fin de que estos no impida el crecimiento, se les debe, no obstante permitir movimientos para evitar la inactividad corporal; y este ejercicio puede obtenerse por varios sistemas, especialmente por el juego; la mayoría de los juegos de la infancia, deberían ser imitaciones de las ocupaciones serías de la edad futura.

En la actualidad, los juguetes, son considerados como cualquier objeto o material que utiliza el niño en sus juegos, dentro de las condiciones necesarias que deben reunir los juguetes son que deben: ser seguros, estimular el juego, facilitar la diversión y el placer, fomentar el desarrollo de las habilidades y destrezas básicas, estimular el pensamiento y la resolución de problemas, favorecer la imaginación creatividad, la participación; deben ser de alta calidad, ser simples y atractivos estéticamente y deben adaptarse al niño ya sus necesidades.

Asimismo, los juguetes se pueden clasificar por edad y por las habilidades y destrezas que estimulen al niño; de allí que hay juegos que estimulen la audición, la observación, la manipulación y los movimientos; así como juegos de ejercicios, simbólicos, de construcción, de reglas, lingüísticos, entre otros (Cordero, 2010).

Así pues, el juego es una actividad que permite a los niños investigar y conocer el mundo que les rodea, los objetos, las personas, los animales, las plantas e incluso sus propias posibilidades y limitaciones. 
Es el instrumento que le capacita para ir progresivamente estructurando, comprendiendo y aprendiendo el mundo exterior, al jugar los infantes desarrollan su imaginación, el razonamiento, la observación, la asociación y comparación, su capacidad de comprensión y expresión contribuyendo así, a su formación integral.

Ahora bien, los juegos como tales tienen la intención de entretener, compartir, diversión o placer o para competir; sin embargo, los juegos con alguna intención didáctica, se convierten en lúdico; se puede decir que en la lúdica los juegos tiene reglas que cumplir, se realiza o se diseña según el contenido de la cátedra y siempre llevan un enfoque o una intención de aprendizaje; cabe agregar que dentro de la neuropedagogía según lo acotado por Jiménez (2007) :

El juego no se puede caracterizar solo como diversión, capricho o forma de evasión, el juego es el fundamento principal del desarrollo psicoafectivo-emocional y el principio de todo descubrimiento y creación, Como proceso ligado a las emociones contribuye enormemente a fortalecer los procesos cognitivos, pues la neocorteza (racionalidad), surge evolutivamente del sistema límbico (emocionalidad). Por otra parte, como practica creativa e imaginaria, permite que la conciencia se abra a otra formas de ser originando un aumento de la gradualidad de la misma, desde esta perspectiva a mayor conciencia lúdica, mayor posibilidad de comprenderse a sí mismo y comprender al mundo (p.82).

\section{Lo Lúdico, el Pensamiento Humano y el Aprendizaje}

El elemento lúdico, estimula y favorece el desarrollo del pensamiento y la creatividad, generando disfrute por la adquisición de nuevos conocimientos, como lo afirma Beltrán (2002):

Para que el aprendizaje funcione adecuadamente es esencial la participación activa del alumno, y la mejor manera de lograrlo sería favorecer todo lo que se pueda el aprendizaje por descubrimiento. Pero esto obliga a presentar la materia instruccional como un desafío a la inteligencia del estudiante que habrá de establecer relaciones, resolver problemas y transferir lo aprendido. Lo más personal del hombre es lo que descubre por sí mismo, y este descubrimiento desarrolla su capacidad mental (p.18).

En tal sentido Beltrán (2002), proyecta la necesidad de que el individuo participe activamente en la construcción de su propio conocimiento, para favorecer sus estructuras mentales, es trascendental que los docentes ofrezcan experiencias donde la persona se enfrente a situaciones reales, que le permitan poner en práctica el conocimiento adquirido, con lo cual se logra la 
Trascendencia de la lúdica como dimensión psicoespiritual en el proyecto de vida de los actantes educativos Nerio J. Ramírez Almarza (10:23)

apropiación de dicho aprendizaje.

Igualmente hay que mencionar lo que establece Medina (2014), el cual considera la lúdica como un:

Conjunto de actividades dirigidas a crear unas condiciones de aprendizaje mediadas por experiencias gratificantes y placenteras, a través de propuestas metodológicas y didácticas no convencionales en las que se aprende a aprender, se aprende a pensar, se aprende a hacer, se aprende a ser, se aprende a convivir y se aprende a enternecer (p.37).

Al tomar en cuenta lo dispuesto por Medina (2014), se hace necesario que los ambientes donde se ofrezcan el aprendizaje sean lúdicos y placenteros para los docentes y estudiantes, con el fin de activar el interés por los temas que se presenten en el entorno educativo, y de allí que los estudiantes estén motivados y dispuestos a mantener una participación más protagónica en las diferentes actividades y a la vez se amplíe la creatividad en el docente y de esta manera pueda desligarse de la rutina, la monotonía y la desmotivación.

Ahora bien, por lo que se ha venido presentando, es necesario acotar que, de acuerdo con Echeverry y Gómez (2009), según la época y los aportes teóricos, la influencia y la relación con las personas, la lúdica se puede categorizar de la siguiente manera:

- Lúdica como instrumento para la enseñanza, donde se agrupan aquellos criterios y posturas que ven en la lúdica una posibilidad didáctica, pedagógica para el proceso enseñanza-aprendizaje.

- Lúdica como expresión de la cultura, donde se reconoce la lúdica como manifestación humana, en la cual dentro de sus interrelaciones en contextos sociales ha producido legados culturales y nuevas expresiones humanas que se configuran dentro de contextos específicos.

- Lúdica como herramienta o juego, logrando recoger diferentes planteamientos que asumen la lúdica como herramienta y lo materializa desde el juego.

- Lúdica como actitud frente a la vida o dimensión humana, dicha categoría, intenta alejarse de la concepción instrumental como herramienta, consideradas acciones y actitudes frente a la vida y que puede estar o no el juego. 


\section{La Dimensión Psicoespiritual de la Lúdica}

Se considera la lúdica como actitud frente a la vida o dimensión humana, como aquella que encamina al hombre al desarrollo emocional, a la capacidad creadora, al desarrollo de los talentos personales para obtener unas actitudes sociales, es decir desarrolla capacidades para establecer relaciones humanas, mejora los talentos personales, el desarrollo de la inteligencia emocional, fomenta la curiosidad y ayudan a alcanzar la felicidad, por tal, la lúdica como dimensión humana contribuye a la construcción cultural humana (Paredez, 2003).

Tomando en consideración la lúdica como actitud frente a la vida, se puede decir entonces que lo lúdico, se convierte en una necesidad vital en el ser humano y por consiguiente, en el docente como uno de los actantes educativos; puesto que, se puede mantener o vivir como un proyecto de vida que intenta dar alcance al equilibrio personal, social, cultural y vocacional; en esta condición la lúdica sumerge los factores humanizadores que necesita la sociedad para alcanzar calidad social, englobando al individuo para poder potenciar las distintas inteligencias y así lograr lo holístico en el ser humano.

Al distinguir la lúdica como una dimensión psicoespiritual en los actantes educativos, esta pasa a ser una competencia desde el plano de la espiritualidad; puesto que, se desarrollará en forma gradual, porque mejorará o incrementará a un nivel óptimo los conocimientos de los docentes, y porque tiene la intención de desarrollar una metanoia en el ser y en la institución; entendiendo metanoia como un cambio profundo generado por la sabiduría espiritual, el reconocimiento del valor del individuo, la unificación de valores, el aprecio por la reflexión y la búsqueda de una alteridad positiva.

El docente al ser formado por la competencia espiritual, desarrollará su perfil lúdico, al cultivar en su ser los valores necesarios para establecer un proyecto de calidad de vida, donde se desarrolle el bienestar personal y social, y por medio de la lúdica, pueda conseguir las dimensiones humanas; potenciar los valores éticos y sociales, los cuales le permitirá un crecimiento personal y comunitario, donde pueda tener un protagonismo de manera positiva, tranquila, optimista y equilibrada; logrando una construcción de su ser interno con ilusión y confianza.

Con esto se quiere significar que, la lúdica no es exclusivamente juegos, sino como aquella educación que es regida de interacción, comunicación y reconocimientos con las demás personas y con los otros contextos culturalmente determinado; por ende, la lúdica es más que una herramienta metodológica, es una estrategia donde se acepta al ser humano tal y como es y que puede ser implementada en el proceso educativo para potencializar el talento de cada persona. 
Trascendencia de la lúdica como dimensión psicoespiritual en el proyecto de vida de los actantes educativos Nerio J. Ramírez Almarza (10:23)

Ahora bien, un docente con perfil lúdico, mantendrá presente actividades que generen novísimos conocimientos, no solo por el hecho de cumplir con el contenido programático, sino por dinamizar el aprendizaje y de invitar a la imaginación espontanea, libre y valorada; con el objetivo de demostrar en las personas que poseen esa habilidad y que pueden acrecentarlo sin miedo ni restricción alguna.

Para Jiménez (2013), la lúdica se considera como una experiencia cultural, es una dimensión transversal que atraviesa toda la vida, no son considerada prácticas, ni actividades, ni es una ciencia, ni una disciplina, ni menos una nueva moda académica, sino que es un proceso inherente al desarrollo humano en toda su dimensión psíquica, social, cultural y biológica; de aquí se desprende que la lúdica está concatenada con la búsqueda del sentido de la vida y a la creatividad del ser humano.

Siendo así, se puede decir que; lo lúdico impregna lo inquieto y espontaneo del hombre, puesto que últimamente los investigadores están afirmando que hasta lo lúdico está introducido en el ácido desoxirribonucleico (ADN); el individuo es un ser que se escudriña en la experiencia, de manera especial en las vivencias de la felicidad, tranquilidad, en el sosiego, en la calma de la vida; por tal, la lúdica es una sensación, una actitud hacia la vida misma, que atrae, cautiva y convence en el sentido íntimo de querer hacerlo, de hacer parte de esto hasta preterir la propia individualidad.

La lúdica es uno de los elementos que estimula el crecimiento de la creatividad en el entorno académico, desarrollar lo lúdico en los estudiantes es fomentar de forma armoniosa e integral las actividades en el recinto pedagógico, pues es a través de ella, que se dinamiza todo accionar y que de una u otra forma, le permite a la persona conocerse, expresarse, sentir y relacionarse con su medio, logrando el disfrute y satisfacción de cada una de sus acciones cotidianas.

Muchos psicólogos han considerado al juego como un elemento liberador de tensiones, afectos y energías, para los psicoanalistas, el juego le sirve al niño para transformar las situaciones no placenteras, en estados placenteros, por ende, el juego es un acto de libre elección, es una de las formas que tiene el ser humano de auto expresarse y auto explorarse; por otra parte, el juego es fundamental en la estructuración del pensamiento infantil, en la construcción del lenguaje y la representación objetiva de la realidad. Los especialistas en psicología y psicopedagogía, utilizan de forma reiterada el juego junto con el dibujo como formas de análisis de la personalidad.

Se puede complementar que, a través de las estrategias lúdicas se invita a los actantes educativos como son los docentes y alumnos a la exploración y a la investigación en torno a los objetivos, contenidos, metodología y evaluación; y a la vez introduce elementos como las imágenes, música, colores, movimientos, sonidos, entre otros; asimismo, permite generar un 
ambiente favorable para que los estudiantes, sientan interés y estén motivados por el aprendizaje que reciben (García, 2004).

En efecto, la lúdica pueda auxiliar al docente a vivir equilibrado en su ser y hacer individual y social, y a través de las diferentes actividades creadoras, el docente asume nuevas concepciones que van más allá de las instrumentales que habitualmente se aferran en los entornos agógicos, asumiendo con ello una coherencia entre la lúdica y sus propósitos.

Por tanto, el docente con perfil lúdico, al desarrollar la lúdica como dimensión humana, va a comprender con mayor proporción todas las expresiones del estudiante y que a su vez le aporte a su noble labor no solo el desarrollo de la creatividad, sino más bien, sentir que su misión de educar se impregne de libertad en su hacer, desear, sentir y aspirar.

La lúdica en el proceso educativo, se asume como un desarrollo integral del ser humano y es tan importante como las dimensiones históricamente aceptadas como la cognitiva, la afectiva, la sexual, la comunicativa y la moral; asimismo, la lúdica, va a promover la realización personal, el bienestar individual y va a mejorar la interacción social.

En definitiva, la lúdica, debe estar presente en los tres grandes campos de la educación como son: pedagogía, andragogía y gerontogogía; debido a que el docente lúdico, va a fomentar en el entorno el desarrollo psicosocial, la adquisición de saberes, la conformación de la personalidad y la personeidad, manifestándola en una gama de actividades pedagógicas, donde estén presente el conocimiento, la innovación, el placer, y el gozo.

Igualmente, al implementar la lúdica en la educación andragógica, se evidencia que el conglomerado alcanza desenvoltura en el aprendizaje y concreción en sus conocimientos, logrando optimar los resultados de cualquier estándar referenciado, y sobre todo el docente formado por la competencia espiritual, permanecerá en una vivencia profesional y vocacional profundizando como aprender nuevas estrategias lúdicas, para que sus estudiantes puedan generar nuevas experiencias y conocimientos y que en su interior sientan satisfacción en lo personal, vocacional y profesional por los resultados obtenidos. 
Trascendencia de la lúdica como dimensión psicoespiritual en el proyecto de vida de los actantes educativos Nerio J. Ramírez Almarza (10:23)

\section{MÉTODO}

Como se expuso anteriormente, el estudio posee una metodología centrada en una revisión bibliográfica o comúnmente denominada documental, este tipo de método tiene como objeto directo la observación de fuentes documentales y es por medio de este tipo de método que se pueden recoger datos de las fuentes primarias, secundarias y terciarias.

De tal manera que, en la indagación, se escogió el tema y los autores, luego se procedió a concretar el tema a investigar, se ubicó suficiente material bibliográfico sobre las categorías: lúdica, dimensión psicoespiritual y actitud ante la vida, se delimitó el objetivo general, se revisó la bibliografía, subrayando, resumiendo y sintetizando el contenido, permitiendo el análisis de las diferentes explicaciones, para luego redactar y engranar las diferentes exposiciones de los autores; seguidamente se elaboró las consideraciones finales, incluyendo algunas recomendaciones del estudio.

\section{CONSIDERACIONES FINALES}

Finalmente puede considerarse que, la dimensión psicoespiritual de la lúdica como actitud ante la vida; va a transformar el proceso de enseñanza-aprendizaje, debido a que son los actantes educativos los protagonistas de dicho proceso, puesto que, son ellos los constructores de su propio conocimiento; por tal, el docente será el oferente de experiencias reales para que el estudiante ponga en práctica el conocimiento adquirido.

Es necesario resaltar que, los docentes deben tener muy claro que la lúdica es una categoría mayor al juego, debido a que, el juego es una de las tantas manifestaciones de lo lúdico, puesto que, la lúdica, tiene el propósito de enseñar según los contenidos programáticos o educativos y los juegos según las neurociencias, contribuyen a fortalecer los procesos cognitivos y de comprender el entorno, así como de desarrollar la imaginación, el razonamiento, la comparación; y de entretener al individuo, entre otras.

En cuanto a la lúdica como actitud frente a la vida; y como dimensión psicoespiritual, se puede decir que, es una de las protagonistas de encaminar al hombre, al desarrollo emocional y el de los talentos personales, ayudando con ello a alcanzar su felicidad; de igual manera, le da equilibrio personal y social a su proyecto de vida, logrando potenciar las distintas inteligencias del ser; por tal el hombre desarrolla una metanoia personal y social, exhibiendo el cultivo de los valores, logrando un crecimiento positivo, actitud optimista, equilibrado, aumentado la confianza $\mathrm{y}$ viviendo con una calidad comunicacional intra y extra personal. 
Se ha de sugerir a los docentes a nivel andragógico que, diseñen actividades, encuentros, convivencias, ejercicios, que persigan no solo el disfrute de esos actos sino del crecimiento psicológico y espiritual de los actantes educativos, para disminuir cualquier tipo de sentimientos que disminuya o anule su felicidad, que mejore el estado de ánimo y la motivación al logro, incrementar el nivel de autoestima, aumento de la integración social, optimizar la expresión verbal y corporal; y mejorar la percepción de las competencias.

Cabe agregar que, dentro de la iniciativa e innovación pedagógica, el docente puede crear y/o modificar cualquier tipo de actividad que conlleve al actante educativo andragógico a desarrollar sus conocimientos, habilidades y destrezas, logrando con ello una metanoia (transformación total) de su personalidad, vocación y profesionalidad, por tal se recomienda; dinámicas de reflexión, dinámicas de presentación, dinámicas de socialización, entre otras. 
Trascendencia de la lúdica como dimensión psicoespiritual en el proyecto de vida de los actantes educativos Nerio J. Ramírez Almarza (10:23)

\section{REFERENCIAS BIBLIOGRÁFICAS}

Cabrera, E. (2009). El Juego Infantil Mediterraneo: Grecia Antigua. Aloma, 39-51.

Cordero, C. (2010). Importancia del Juego y los Juguetes para el desarrollo integral del niño de educación infantil. Autodidacta, 10-20.

Echeverri, J. y. (2009). Lo lúdico como componente de lo pedagógico,la cultura, el juego y la dimensión humana. Pereira: UTP.

Flaceriére, R. (1993). La vida cotidiana en Grecia en el siglo de Pericles. Madrid: Temas de Hoy.

Jiménez, C. (2007). Neuropedagogía, Lúdica y Competencia. Bogotá: Cooperativa Editorial Magisterio.

Newson, J. (1986). Juego y objetos para jugar. Barcelona: CEAC.

Soriano, J. (2013). La actividad ludica como herramienta para el desarrollo del actor. Escritos en la Facultad, 56-68 .

Universidad del Norte. (2010). Historia de la educación mundial: la educación en Roma. Creditos, 2-7. 
Trascendencia de la lúdica como dimensión psicoespiritual en el proyecto de vida de los actantes educativos Nerio J. Ramírez Almarza (10:23)

\section{Referencias Electrónicas}

Jiménes, D.(18 de Diciembre de2013). Nuevatribuna.es. Obtenido de Para qué sirve la Educación:http:// www.nuevatribuna.es/opinion/daniel-molina-jimenez/sirve-educacion/20131218174552099326. html

Medina, G. (20 de Octubre de 2014). Gramática de la ternura. Obtenido de https://docs.google.com/ document/d/18Nq4S3fUUQVHST8Rsg264pD8JeYgDG4 fjpw424rd2Hc/edit?pli=1

Paredez, J. (15 de Septiembre de 2003). Deporte. Recuperado el 14 de Junio de 2016, de Actividad lúdica y proyecto de vida.: http://www.efdeportes.com/Revista Digital 